\title{
Development of an Oral Health Survey: Columbus, Ohio
}

\author{
Raymond A. Kuthy, DDS, MPH ${ }^{\star}$ \\ Assistant Professor, Community Dentistry \\ Ohio State University College of Dentistry \\ 305 W. 12th Avenue, Box 201 \\ Columbus, Ohio 43210-1241
}

\section{Barbara W. Martin, RDH, MS}

Dental Research Program Coordinator

Ohio Department of Health, Division of Dental Health

Columbus, $\mathrm{OH}$

Mark D. Siegal, DDS, MPH

Director, Community Dental Programs

Columbus Health Department

Columbus, $\mathrm{OH}$

\section{Stephen A. Eklund, DDS, DrPH}

Associate Professor

Program in Dental Public Health

School of Public Health

University of Michigan

Ann Arbor, Ml community-specific data to respond to the changing needs of the populations they serve. Although a general decline in dental caries has been observed over the past two decades (3-6), the disease still affects most children and adults and must be monitored. Demographic shifts in the proportion of elderly individuals in this country will likely result in an increased prevalence of periodontal diseases $(7,8)$, and lead to a greater need and demand for preventive services.

The ability to assess a population's oral health status quickly and economically may enable a state or local program to plan and implement cost-effective public health strategies to meet that community's specific needs $(8,9)$. Periodic statewide or local oral health surveys can enhance this ability, while serving as a mechanism for program evaluation. The purpose of this article is to describe the manner in which the Columbus Health Department and the Ohio Department of Health conducted a local oral health survey as a basis for program planning.

\section{Background}

The Columbus oral health survey grew out of the state and local health departments' need for oral health status data, primarily for planning purposes. The planning process for the survey was a collaborative effort among representatives of both health departments, the Ohio State University's College of Dentistry, and the University of Michigan's School of Public Health.

The Division of Dental Health, Ohio Department of Health $(\mathrm{ODH})$, undergoes an in-depth strategic planning process at five-year intervals. This process requires the division to design specific strategies that will
* Send correspondence and reprint requests to Dr. Kuthy. Manuscript Received: 6/3/87; returned to authors for revision: 7/29/87; accepted for publication: $8 / 27 / 87$. 
have an impact on the oral health status of target populations. Division efforts have been concentrated on community water fluoridation and school-based fluoride mouthrinsing programs since the most recent plan was developed in 1981 (10). Information to plan initiatives or redirect existing programs was lacking.

The Columbus Health Department (CHD) was in the process of converting its long-standing clinical dental program into one focused on community-based oral disease prevention. Columbus-specific data on local oral health status were considered an important element in planning the new program.

An advisory group of dental professionals from $\mathrm{ODH}$, two dental schools, and several local health departments was convened during the autumn of 1985 to discuss a statewide oral health survey. The group agreed first to conduct a pilot survey in fluoridated Columbus for the purpose of developing, evaluating, and refining a data collection method prior to the initiation of a statewide effort. The following methodology was developed by a three-member subcommittee.

\section{Sample Selection}

The determination of a sample for the survey resulted from decisions on age cohorts, site selection, and the ability to recruit volunteers at each site. Four age groups were examined: (1) children, grades $1-2$; (2) children, grades 6-7; (3) adults, 35-44 years; and (4) adults 65 years and older. Except for the youngest cohort, these groups are consistent with previous World Health Organization (WHO) Pathfinder survey recommendations (11). Furthermore, they represented likely target populations for CHD or OHD treatment and prevention programs, such as dental sealants.

\section{"Accessing a representative number of adults to examine was the biggest problem encountered by the survey planners."}

Sample selection was accomplished using a stratified cluster technique. Six sites per age group were selected; attempts were made to recruit $20-30$ subjects per site. For the children's cohorts, 12 schools (six elementary and six middle) were randomly selected from among four strata based on the percent of children participating in a free or reduced-cost meal program at each school. The intent was to account for differences in socioeconomic status. School principals were requested to select classrooms at each grade level and all children in those classrooms were given consent forms for parental approval.

The survey of adult cohorts required several methodological and logistical changes. It was more difficult to identify sites that represented a cross-section of Colum- bus residents in these age ranges. For the 35-44-yearoldgroup, sites were selected from among those businesses and community centers with which the Columbus Health Department had a previous working relationship. Consultation with an administrator from the organization that operates the citywide congregate meal site program identified senior recreation centers and subsidized housing communities that served a wide range of senior citizens with different economic, age, and racial backgrounds.

\section{Examiner Training}

The six examiners included faculty from the Ohio State University College of Dentistry plus staff from both the city and state health departments. Recorders were secured from ODH. Following selection of examiners and recorders, a one-day training session was conducted to review examination procedures for the children and to familiarize recorders with computerized direct data entry. Trial examinations were conducted at a middle school on volunteer students. Each volunteer had multiple examiners score the dentition. Although several people examined each child, neither tests for intra- nor interexaminer reliability were conducted.

A half-day training session was conducted at $\mathrm{CDH}$ in preparation for the adult examinations. The examiners who performed the periodontal assessment had an additional half-day session to maximize their consistency. Again, volunteers from both age cohorts were recruited for the training session.

\section{Exam Criteria}

Both primary and permanent teeth were examined for each child using portable dental chairs, fiberoptic lights, plane mouth mirrors, and explorers. No radiographs were taken. The principles of caries detection, those used in the 1979-80 National Dental Caries Prevalence Study (Swango, personal communication, 1979), served as the basis for the development of examination criteria for both the child and adult surveys. An explorer was only used when a visual examination left a question as to the presence of dental caries.

The status of each tooth and tooth surface was indicated by the assignment of a code (Table 1 ). The priority for multiple options on one surface (or tooth) was caries, then filled (or crowned), followed by sealed (or questionable), and finally a sound surface. Thus, a sound surface (or tooth) only existed in the absence of one of the other codes.

The adult survey was conducted by two examiners at each site. One examiner conducted an assessment of coronal and root surfaces of the teeth while the other checked the prosthetic status, performed a periodontal evaluation using a modified Community Periodontal Index of Treatment Needs (CPITN), and examined the soft tissues for suspicious areas.

The coronal coding system (Table 2), but not the codes, for the adults was similar to the children's examination with the following exceptions: third molars were included, a code for fixed pontic replacement was 
TABLE 1

Tooth/Surface Codes for Children

\begin{tabular}{|c|c|c|c|}
\hline & Primary & Permanent & Both \\
\hline Sound & 0 & 1 & - \\
\hline Decayed & 2 & 3 & - \\
\hline Filled & 4 & 5 & - \\
\hline Crowned & 6 & 7 & - \\
\hline $\begin{array}{l}\text { Missing (other than } \\
\text { caries) }\end{array}$ & - & 8 & - \\
\hline Unerupted & - & 9 & - \\
\hline $\begin{array}{l}\text { Examiner suspects } \\
\text { pulpal involvement }\end{array}$ & - & - & $\mathrm{E}$ \\
\hline $\begin{array}{l}\text { To be extracted (beyond } \\
\text { restorative care) }\end{array}$ & - & - & $x$ \\
\hline Partially erupted* & - & $P$ & - \\
\hline Sealant present & - & 一 & $S$ \\
\hline $\begin{array}{l}\text { Injury (restorative } \\
\text { procedure needed) }\end{array}$ & - & - & I \\
\hline Missing (caries) & & M & - \\
\hline $\begin{array}{l}\text { Questionable lesion } \\
\text { (examiner unable to } \\
\text { decide if area is } \\
\text { carious) }\end{array}$ & - & - & $Q$ \\
\hline
\end{tabular}

*Occlusal surface not completely exposed (mandible), or tissue covering the area mesial to the oblique ridge (maxilla).

TABLE 2

Tooth/Surface Codes for Adults

$0=$ Sound

$1=$ Decayed

$2=$ Filled

$3=$ Crowned (due to caries)

$4=$ Crowned (injury, esthetics)

$5=$ Missing (caries), no replacement

$6=$ Missing (other than caries), no replacement

$7=$ Missing, with replacement (i.e., pontic)

$8=$ Unerupted tooth

$9=$ Other (e.g., primary tooth)

$E=$ Examiner suspects pulpal involvement

$\mathrm{X}=$ To be extracted

$I=$ Injury (restorative procedure needed)

$\mathrm{Z}=$ Edentulous arch

established, subjects were questioned about the reasons for teeth having been crowned (i.e., caries, injury, esthetics, bridge abutments); and there was a single code for an edentulous arch.

Each tooth was examined for root caries immediately after the coronal examination. Root caries were recorded when the lesion was situated below the cementoenamel junction and there was gingival recession (12). The examiner judged whether existing restorations resulted from root caries or toothbrush abrasion.

A second examiner asked each adult about the ownership of a partial or full denture, inspected the prosthetic appliance (if present), and then assigned a code
TABLE 3

Adult Prosthetic Codes (Existing Condition)

$0=$ No prosthesis

$1=$ Wears full denture

$2=$ Has full denture, but doesn't wear it

$3=$ Wears partial denture

$4=$ Has partial denture, but doesn't wear it

$5=$ Full denture broken

$6=$ Partial denture broken

TABLE 4

Modified CPITN Codes

$0=$ No signs of disease

$1=$ Gingival bleeding $(0-30$ seconds after probing)

$2=$ Supragingival calculus, overhangs of restorations

$3=$ Subgingival calculus alone, or in combination with supragingival calculus

$4=$ Pockets, $3.5-5.5 \mathrm{~mm}$ deep

$5=$ Pockets, $>5.5 \mathrm{~mm}$

$6=$ Missing tooth

$7=$ Indicated for extraction due to periodontal condition (e.g., vertical mobility)

for the prosthetic condition (Table 3). No determination was made about the fit of the denture, only whether or not it was intact or broken.

CPITN codes were modified according to Table 4. The WHO periodontal probe was used in determination of pocket depth, calculus, and bleeding upon probing (13). All teeth, including third molars, were examined. Two areas of the maxillary teeth (midbuccal and the mesio-buccal line angle) and the mandibular teeth (mid-lingual and the mesio-lingual line angle) were examined. The poorer of the two scores was recorded for each tooth.

Upon completion of the above examinations, the oral soft tissues were observed for suspicious conditions. Only three codes $(0=$ no suspicious area, $1=$ suspicious area, nondenture bearing, $3=$ suspicious area, denture bearing) were used to indicate soft tissue status. When a suspicious pathologic condition existed, the examiner recommended that the subject visit a dentist for further evaluation. No determination was made on the type of "suspicious area" that was observed nor on its precise location.

\section{Site Logistics}

Examinations of children were conducted at the 12 schools over a two-week period. Each exam took approximately 3-4 minutes to conduct for these two age groups. An examiner was assigned to no more than three schools.

The adult exams were conducted over a six-week period. These exams generally required $10-15$ minutes per dentate subject. A signed consent form was obtained from each subject prior to the examination. This 
consent form also contained a brief medical history designed to identify those individuals for whom a periodontal assessment would be contraindicated (8).

\section{Direct Data Entry}

Data were directly entered into portable microcomputers. This method allowed for a quick analysis of general information about the groups studied. Further, the assistance of an experienced programmer minimized the chance for error in data entry. At the start of each day, the program prompted the recorder for information on the site code, date of the exam, and the initials of the examiner. The program then automatically entered this information on each subject's data screen that day.

Prior to the individual examination, the following information was entered into the computer: patient identification number, gender, date of birth, and race. After the completion of examinations at a site, the data diskette was duplicated and one copy submitted for analysis.

\section{"We are not suggesting that these procedures supplant WHO's Basic Methods for Oral Health Surveys, but rather that they serve as a step in adapting Pathfinder to the needs of public dental programs in this country."}

The program was designed to enter default codes for various items. For instance, when a child's tooth was sound ( 0 or 1$)$, that code was automatically entered for all the surfaces; thus, it expedited the process, especially in the lower grades. In adults, a single code for an edentulous arch $(Z)$ would default for all the teeth and the tooth surfaces of that arch.

\section{Discussion}

The WHO Pathfinder method was developed as a means of providing data for the planning of basic oral health care services, for minimal oral disease surveillance, and for the replanning of services over time (11). Pathfinder was developed primarily to assist developing countries with limited resources-those that had neither the manpower, the time, nor the financial means to conduct a comprehensive survey. These constraints, however, are not unique to developing countries. Indeed, they prevail to a degree in this country, and certainly were acknowledged as present by the survey planning committee.

For the children examined, two major outcomes were sought: the dental health status of children in each grade, and the need for sealants among this population. The prevalence of pit and fissure sealants, in combination with the eruption patterns of posterior teeth
TABLE 5

Treatment Urgency Classification for Children

$0=$ No obvious need for dental treatment at this time. Your child should, however, visit a dentist at least once a year for a more complete examination including $x$-rays, if needed.

$1=$ Need for dental treatment of a nonurgent nature. Please take your child to a dentist within the next two months.

$2=$ Need for early dental treatment due to obvious cavities. Please take your child to a dentist as soon as possible within the next few weeks.

$3=$ Need for immediate dental treatment due to a toothache or infection. Please take your child to a dentist right away.

and the prevalence of decayed/filled tooth surfaces, would allow planners to target grade levels for a sealant program. Grade levels rather than age were a selection variable, because school-based prevention programs would be implemented on that basis.

In an attempt to achieve greater participation, the authorizing parental permission letter indicated that the health department would notify them of their child's dental condition. A treatment urgency letter with broad categories of dental need was sent home to the parent (Table 5). The examiners provided the school nurse with a list of children who required immediate dental care.

The objectives of acquiring local information on the oral health status and treatment needs of Columbus children and applying that information in program planning have been met. This pilot survey has set the framework for implementing a similar school-based survey on a statewide basis.

Accessing a representative number of adults to examine was the biggest problem encountered by the survey planners. A major deterrent of this study was that the target of 20 to 30 people per site was met at only four of 11 original adult sites: two senior citizens' centers and two work sites for 35-44 year olds. Additional data were subsequently collected at other examination sites.

While participation was great at work sites, sampling from only these settings would certainly bias the measures of disease status and treatment needs among this age group. Prior to expanding the adult phases of the survey statewide, more attention needs to be given to accessing adults who are infrequent dental users.

In the light of the objectives for the survey, the group decided the strength of the CPITN was in its feature of characterizing periodontal treatment needs (14). Since the purpose of this survey was to acquire information to guide the agencies in the development of prevention and treatment programs, identifying only epidemiologic characteristics of these diseases would not have fulfilled this mission.

The CPITN method notes the worst score for indexed teeth in each of the sextants in the mouth to be recorded (13). If index teeth are absent, then all remaining teeth 
are examined. Teeth that are indicated for extraction because of vertical mobility are not considered and there is no differentiation between teeth with supraand subgingival calculus. Further, no clear indication existed in the literature as to the probing sites. The modifications that were developed by the survey planners may be beneficial in better approximating the actual treatment needs. The investigators currently are determining whether the indexed teeth are representative of a sextant in this population.

The survey of Columbus residents was conducted without a formal budget. All of the manpower was donated, and equipment that was not available at the local health department was borrowed from universities, state health departments, or local dental programs. Using available personnel and dental programs not only enabled this survey to be conducted, but also increases the likelihood that subsequent surveys will be possible.

We are not suggesting that these procedures supplant WHO's Basic Methods for Oral Health Surveys, but rather that they serve as a step in adapting Pathfinder to the needs of the public dental programs in this country. Only after other improvements will a solid standard develop.

Based on the Columbus survey, the planning committee has expanded the scope of the survey to the entire state. Careful analyses and interpretation of the existing data will enable local and state agencies to improve upon data collection methods.

\section{References}

1. The prevalence of dental caries in United States children: the National Dental Caries Prevalence Study 1979-80. US Department of Health and Human Services. NIH Pub No 82-2245, Dec 1981.

2. Horowitz HS. The National Institute of Dental Research's 1985 survey of working and senior adults. J Public Health Dent 1985 Fall; $45: 227-8$

3. Graves RC, Stamm JW. Oral health status in the United States: prevalence of dental caries. J Dent Educ 1985 Jun;49:341-5.

4. Brunelle JA, Carlos JP. Changes in the prevalence of dental caries in US schoolchildren, 1961-1980. J Dent Res 1982 Nov;61 (Spec Iss): $1346-51$

5. Burt BA. The future of the caries decline. J Public Health Dent 1985 Fall;45:261-9.

6. Mandel ID. Changing patterns of dental caries. Quintessence Int 1985 Jan;51:43-6.

7. Douglass CW, Gammon MD. Implications of oral disease trends for the treatment of older adults. Gerodontics 1985 Apr;1:51-8.

8. Hunt RJ, Beck JD. Methodological considerations in a dental epidemiologic survey of an elderly population. J Public Health Dent 1985 Fall;45:257-60.

9. Cons NC, Beck JD, Field H, Ettinger R, Jakobsen J. A low-cost method for conducting a statewide survey of oral health. J Public Health Dent 1983 Fall;43:295-304.

10. Easley MW. Division of Dental Health. Finding new ways to prevent disease, promote health. Ohio Dent J 1982 Mar;56:44-9.

11. Oral health surveys. Basic methods. 2nd ed. Geneva World Health Organization, 1977.

12. Katz RV. Assessing root caries in populations: the evolution of the root caries index. J Public Health Dent 1980 Winter;40:7-16.

13. Ainamo J, Barmes D, Beagrie G, Cutress T, Martin J, Sardo-Infirri J. Development of the World Health Organization (WHO) Community Periodontal Index of Treatment Needs (CPITN). Int Dent ] 1982 Sept;32:281-91.

14. Barmes DE, Leous PA. Assessment of periodontal status by CPITN and its applicability to the development of long-term goals on periodontal health of the population. Int Dent J 1986 Sept;36:177-81. 